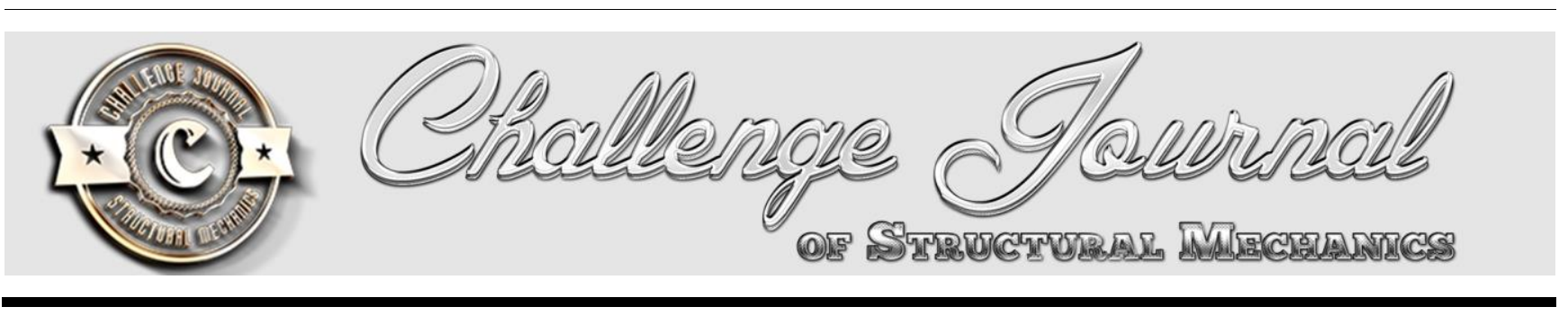

\title{
FRP-RC/PC members subjected to combined actions
}

\author{
A. Ghani Razaqpur ${ }^{a}$, Francesco Bencardino ${ }^{\text {b }}$, Lidia Rizzuti ${ }^{b}$, Giuseppe Spadea ${ }^{\text {b,* }}$ \\ ${ }^{a}$ Department of Civil Engineering, McMaster University, Hamilton, Ontario L8S 4L8, Canada \\ ${ }^{\mathrm{b}}$ Department of Civil Engineering, University of Calabria, V. P. Bucci, 87036 Rende (CS), Italy
}

\section{ABS T RACT}

The capacity provisions of conventional Reinforced Concrete (RC) and Prestressed Concrete (PC) beams subjected to combined action of torsion, shear and flexure are well known and stated by international/national codes. Similar provisions lack for concrete members containing Fibre Reinforced Polymer (FRP) reinforcements. In general, there is paucity of research on the treatment of torsion combined with other stress resultants for FRP-RC/PC members. In this paper, the theoretical method proposed by the Canadian standard CSA S806 for FRP-RC/PC structures is presented. The critical issues, related to this topic, such as the appropriate strength and inclination of the diagonal struts and failure criteria are critically analyzed and addressed. In order to assess the reliability of this study a comparison between available experimental data regarding FRP-RC/PC beams subjected to combined actions and their corresponding theoretical provisions derived by the CSA S806 standard is shown. Furthermore, another approach, available in literature, which is based on the space truss model, is examined and used for comparison in order to evaluate the theoretical provisions offered by this model against the tests value of the set of the beams analyzed in this study. Based on the critical analysis of the results, it can be highlighted that the CSA method is able to conservatively predict the capacity of these beams.
\end{abstract}

\section{ARTICLE INFO}

\section{Article history:}

Received 4 January 2015

Accepted 17 February 2015

\section{Keywords:}

Combined actions

FRP bars/tendons

RC/PC members

Standards

Torsion

\section{Introduction}

Reinforced Concrete (RC) and Prestressed Concrete (PC) members can be subjected to torsion combined with other actions like shear and/or flexure. For conventional RC and PC structures, refined models have been developed to analyse the interaction of bending moment, shear force, and torsional moment. One of the early models developed on this topic is the one based on the skewbending approach proposed by Elfgren et al. (1974), which is based on equilibrium considerations. It predicts the torsional capacity of the member without giving any indication about its deformations. Other semi-analytical and empirical models, some based on variable angle Space Truss Model (STM) of Rabbat and Collins (1978), or Compression Field Theory (CFT) of Collins and Mitchell (1997) and of Rahal (2007) have been developed for torsion combined with other actions. Further models proposed by Navarra-Gregori et al. (2007) and Swamy
(1962) are available in literature. Some of these methods are included in concrete design codes such as the AASHTO LRDF (2012), the ACI 318 (2011), the CSA A23.3-04 (R2010), and the Eurocode (2004). The American Bridge Code AASHTO LRDF and the Canadian Standard CSA A23.3 include a design method based on the Modified Compression Field Theory (MCFT). This method, named as General Method (GM) (Collins et al., 1996; Rahan and Collins, 1999), accounts in a rational way how shear and torsion affect the stresses in the longitudinal steel located in the cross section. Similarly the procedure proposed by the ACI 318, is based on the thinwalled tube scheme and, space truss analogy. In all these three Code methods, the equations are suitable for designing sections subjected to shear, bending moment, axial load, and torsional moment. They are not suitable, however, for analysis of unsymmetrically reinforced sections if both flexural and torsional moments are acting.

* Corresponding author. Tel.: +39-0984-496919 ; Fax: +39-0984-496918 ; E-mail address: g.spadea@unical.it (G. Spadea) ISSN: 2149-8024 / DOI: http://dx.doi.org/10.20528/cjsmec.2015.02.001 
The use of Fibre Reinforced Polymer (FRP), as an alternative to conventional steel reinforcements in concrete members is on the rise, particularly when the longterm durability of reinforced concrete structures that are built in area with aggressive environment is the main concern. Indeed FRP reinforcements show advantageous properties, compared to conventional steel reinforcements, in terms of higher strength, durability, magnetic transparency, insulation, and lightweight. Nevertheless, FRP reinforcements have some shortcomings. In fact, unlike conventional steel bars FRP materials do not display plasticity and, exhibit very low shear strength, a lower elastic modulus. In general structures with FRP reinforcements are characterized by a clear lack of ductility. Based on these considerations, the design procedures developed for conventional RC or PC cannot be directly applied to FRP-RC/PC members. It has already been shown that new design methods are necessary for FRP RC sections subjected to shear and flexure (Ascione et al., 2010; Razaqpur and Spadea, 2014; Ascione et al., 2014). As a result, design codes and guidelines aimed at FRP-RC/PC structures ACI 440.1R (2006), ACI 440.4R (2004), CNR-DT 203 (2006), CSA S806 (2012), Fib 40 (2007), JSCE (1997) are available.

These guidelines, codes and standards give specific indications for bending and shear design while in some of them there is lack of specific provisions for the design of FRP-RC/PC members subjected to combined action of torsion, bending and shear. The latter may be partly due to the belief that torsion is regarded as secondary effect and not explicitly considered in design. In reality it is not always negligible and should be considered similar to other load effects, particularly if torsional moment is necessary for satisfying the equilibrium requirements. Actually, many structural elements such as spandrel beams, eccentrically loaded bridge girders, and beams curved in plan are subjected to the effects of combined actions. Moreover, there is a paucity of sufficient experimental and theoretical analysis about the behavior and the strength of FRP-RC/PC members.

However, if FRP reinforcement has to become a credible alternative to steel reinforcement, it is necessary that designers become familiar with suitable methods for designing FRP-RC/PC structures against any action and to their combination to which they may be subjected. As stated earlier, only few researches were developed by Probaghar and Kumaran (2011), Ragab and Eisa (2013) Razaqpur et al. (2011) about FRP-RC/PC members under pure torsion and by El-Awady et al. (2013) about FRP-RC members under combined torsion and flexure.

The new edition of the Canadian Standard CSA S806 furnishes detailed equations for the analysis and design of torsion combined with other stress resultants for FRP$\mathrm{RC} / \mathrm{PC}$ members. In this paper the background to the development of the provisions provided in the Canadian Standard is described, the key parameters that govern this topic are identified and discussed and the underlying arguments for the selection of the values of these parameters for FRP-RC/PC members are presented. The accuracy of the model proposed by the Canadian Standard is checked by comparing the predicted ultimate load of a number of FRP-RC/PC members involving carbon FRP (CFRP) and aramid FRP (AFRP) as both longitudinal and transverse reinforcement with the their corresponding experimental values. Admittedly, the amount of experimental is relatively limited, but for the purpose of the preceding comparison, all usable experimental data in the open literature are used. The recorded failure loads are also compared with the corresponding ultimate load computed by using Zhou's method (1997), which is an adaptation of the torsional design method in the Japanese Society of Civil Engineering (JSCE) concrete design standard.

It is important to emphasize at the outset that the focus of the current study is on the ultimate load, thus the statistical variability of the member material and geometric properties and their effect on ultimate loads are not germane to the study. When assessing a model's accuracy by comparing its predictions with experimental data from laboratory specimens, the specimens' material and geometric properties are known while statistical variability is reflected by the resistance factor which is obtained through reliability analysis. The results of the current study would provide the so-called model error for deriving the reliability-based resistance factor.

\section{Theoretical Model and Basic Assumptions for RC and/or PC Members}

As a prelude to the development of the design calculation procedure for FRP-RC/PC members subjected to combined actions, first the calculation method for conventional RC/PC members is briefly discussed. Design provisions for RC and PC beams subjected to combined torsion, shear and flexure actions assume that moment and axial forces acting on the cross section are resisted by normal stresses in the chords, while concomitant shear and torsion are resisted by shear flow in the walls of an equivalent hollow section. Due to different shear flows and the different strain conditions in the chords adjacent to the walls, the angle of inclination of the principal compressive stress, $\theta$, will differ in each of the walls.

In the case of pure torsion, the diagonal stresses spirals around the member at a constant angle, while for zero torsion the diagonal stresses in the side walls are parallel. Furthermore, in the wall where shear stresses due to torsion and shear add, the angle $\theta$ is not greatly influenced by the loading ratio. In a solid section, it is normally assumed that the shear stresses due to the shear force are resisted by the solid section while the shear stresses due to torsion are resisted by the walls of an equivalent hollow section with wall thickness, $t_{w}$, and the area, $A_{o h}$, enclosed by the centerline of its walls. Thus, under the combined actions the longitudinal strains and the inclination $\theta$, of the principal compressive stresses vary over the depth of the beam.

Theoretically, $t_{w}$ is function of the angle of inclination of the struts $\theta$, which in turn is function of the value of $v / f_{c}$ and longitudinal strain $\varepsilon_{\ell}$. With $v$ the maximum shear stresses and $f_{c}$ is the concrete compressive strength. The angle $\theta$ can be computed using strain compatibility and 
equilibrium requirements, but the procedure is iterative. This circumstance is not convenient in design. Consequently, some code, suggest to put $A_{o}=0.85 A_{o h}$, where $A_{o h}$ and $A_{o}$ are the areas enclosed by the centerlines of the hoops and the hollow tube, respectively, which allows one to determine $t_{w}$. To avoid iteration when designing a section against combined actions, the CSA A23.3 and AASHTO LRDF recommend that $\theta$ be calculated by using

$\theta=29+7000 \varepsilon_{l}$

where $\theta$ is expressed in degrees. Here, the longitudinal strain $\varepsilon_{\ell}$ can be calculated by using the following expression

$$
\varepsilon_{l}=\frac{\frac{M_{n}}{d_{v}} \sqrt{\left(V_{n-} V_{p}\right)^{2}+\left(\frac{0.9 p_{h} T_{n}}{2 A_{o}}\right)^{2}}-A_{p} f_{p o}}{2\left(E_{l} A_{l+} E_{p} A_{p}\right)},
$$

where $M_{n}, V_{n}$ and $T_{n}$ are the ultimate moment, shear strength and torsion at the section of interest (replaced by the factored moment, shear strength and torsion when designing), $V_{p}$ is the component of the prestressing force at section opposing the applied shear force, $d_{v}$ is the effective depth, taken as the greater of $0.9 d$ or $0.72 h$, where $d$ is the distance from the extreme compression fibre to the centroid of tension reinforcement and $h$ is the overall height of the member, $p_{h}$ is the length of the centerline of the hoop used as torsion reinforcement, $A_{p}$ is the cross sectional area of the prestressed tendons, $f_{p o}$ is the effective stress in the prestressing tendons, $A_{l}$ and $A_{p}$ are the total area of non-prestressed and of prestressed longitudinal reinforcement in the cross-section respectively, $E_{l}$ and $E_{p}$ are the elastic moduli of non-prestressed and of prestressed longitudinal reinforcement in the tube cross-section.

Notice that Eqs. (1) and (2) allow one to compute $\theta$ as function of the rigidity of the longitudinal reinforcing and prestressing steel as well as the level of prestressing. Accordingly, one can adapt them for FRP-RC/PC members by inserting the appropriate axial rigidity of the FRP reinforcing/prestressing in Eq. (2) in lieu of that of steel. The substitution of steel rigidity by FRP rigidity is reasonable and the favourable agreement between the predicted and measured torsional strength values in this work indirectly supports the claim. However, more substantive support is provided by the work of Kanakubo and Shindo (1997).

On the side of the beam where the shear and torsional stresses are additive the shear stress can be evaluated, for solid section where significant redistribution of the shear stress is possible, by the following expression

$v=\sqrt{\left(\frac{V_{n-V_{p}}}{b d_{v}}\right)^{2}+\left(\frac{T_{n}}{1.7 A_{o h} t_{w}}\right)^{2}}$

where $b$ is the effective width of the section.

Once the tube dimensions and $\theta$ are known, the member nominal torsional, $T_{n}$, and shear strength, $V_{n}$, can be determined according to the Standard.

\section{Application of the CSA Method to FRP-RC/PC Members}

According to CSA S806, Eqs. (1) to (3) are applicable to FRP-RC/PC members with the following changes

(a) In Eq. (1) the constant 29 on the right-hand side is replaced by 30 .

(b) In Eq. (2) the parameters $E_{l}\left(E_{p}\right), A_{l}\left(A_{p}\right)$ for steel reinforcement (prestressing steel) are replaced by the corresponding properties of FRP reinforcing and prestressing bars, i.e. by $E_{F}\left(E_{F p}\right)$ and $A_{F}\left(A_{F p}\right)$, respectively.

(c) In Eq. (3) to avoid premature crushing of the diagonal struts the following limits should be satisfied

$v \leq 0.2 f_{c}^{\prime}$

The thickness $t_{w}$ is assumed to be not greater than either the ratio $A_{o h} / p_{h}$ or two times the minimum clear cover to the closed transverse torsion reinforcement. (d) In the following equation to compute the torsional strength

$T_{n}=2 A_{o} \frac{A_{t} f_{y t}}{s} \cot \theta$

the parameter $A_{t}$ is replaced by the area of the FRP transverse reinforcement, $A_{F t}$, and the yield strength of the transverse steel reinforcement, $f_{y t}$, are replaced by 0.4 $f_{\text {Fut, }}$ where $f_{\text {Fut }}$ is the ultimate or rupture strength of the transverse (hoops) FRP reinforcement used for torsion. It should be mentioned that $f_{F u t}$ is the strength of a straight FRP bar with identical size and composition as the FRP hoop.

As stated before, FRP reinforcement differs from steel in a number of ways. FRP bars are transversely isotropic where the fibers are aligned along the longitudinal axis of the bar while steel is isotropic. FRP bars have a significantly higher strength and stiffness along the bar than perpendicular to the bar. FRP bars behave linear elastically up to failure and compared to steel bars they typically have much higher tensile strength, lower elastic modulus and lower ultimate strain. Therefore, in adapting the steel reinforced concrete designs methods to FRP, these characteristics of FRP and their effect on the strength of FRP reinforced members need to be recognized. It is important to point out that the fundamental space truss model that forms the basis of torsional strength equations in reinforced concrete design codes is independent of the reinforcement properties. The reinforcement properties affect the strength of the truss members and the inclination of its diagonal members, but not the truss model per se. This is the reason for the similarity of the equations used to determine the strength of FRP-RC/PC members with corresponding equations for steel reinforced members.

\subsection{Analysis of FRP versus steel transverse reinforcement}

When a reinforcing bar is bent in the shape of a stirrup or hoop, the axially stressed hoop will be subjected to radial compressive stress in its corner. The magnitude of this stress depends on the ratio $r_{b} / d_{b}$ and the magnitude 
of the axial stress in the bar, where $r_{b}$ is the radius of the bend and $d_{b}$ is the diameter of the bar. The radial stress $\left(\sigma_{r}\right)$ combined with the axial stress $\left(\sigma_{l}\right)$ in the bar creates a state of biaxial stress at the bent corner. The radial stress is generally smaller than the axial stress; therefore, in the case of steel rebar, which are isotropic and ductile, the effect of radial stress is relatively small and it can be safely ignored. In the case of FRP bars, due to the smaller strength and modulus of the bar in the radial than the longitudinal (circumferential) direction and the biaxial tensile-compressive state of the stress at the bend, the bent bar fails at a lower axial load than a similar straight bar. The failure envelope for this biaxial state of stress is theoretically not only function of the geometric parameter $r_{b} / d_{b}$, but also of the fiber and resin type and the bar fiber content. In the ACI 440 and in the JSCE guideline an equation is proposed to evaluate the tensile strength of the FRP bent bar. The CSA S806 adopted a safe limit for design by analyzing the results of the formula proposed by the ACI guideline against the experimental data available in literature. It is recognized that this assumption may yield a conservative estimate of the nominal torsional strength of FRP-RC/PC members, but is practically more convenient because it does not require knowledge of the hoop bend angle at the design stage.

\subsection{Diagonal cracks angle, $\theta$}

An important parameter that need be determined is the angle $\theta$, which can be calculated using Eq. (1). Since $\theta$ is given as function of the longitudinal reinforcement rigidity, it can be calculated if in Eq. (2) the steel elastic modulus, $E_{1}\left(E_{p}\right)$, is replaced by the corresponding FRP elastic modulus, $E_{F}\left(E_{F p}\right)$. The angle $\theta$ is known to vary depending on the beam properties and for this reason the ACI 318 allows any value of $\theta$ between $30^{\circ}$ and $60^{\circ}$, but suggests $\theta$ be taken as $45^{\circ}$ for reinforced concrete members and $37.5^{\circ}$ for prestressed concrete members. While selecting a suitable angle when designing a steel reinforced member for torsion is justifiable because equilibrium requirements can be satisfied for any reasonable value of $\theta$, assessing the strength of existing members requires more accurate calculation of the angle $\theta$, for neither $\theta=45^{\circ}$ nor any other arbitrarily fixed value is likely to give an accurate estimate of the actual strength of every member. In the case of FRP reinforced members, the assumption of $\theta=45^{\circ}$ may not be appropriate even for design purposes, especially for calculating the amount of transverse reinforcement, because such an assumption treats all types of FRP reinforcement the same, irrespective of the substantial differences that exists among the mechanical properties of different types of FRP. There would be little theoretical justification for such an assumption and in certain cases it could lead to a substantial overestimation of the strength of a member.

Since Eq. (1) for computing $\theta$ accounts for the effect of the axial rigidity of the longitudinal reinforcement on the inclination of the diagonal cracks, the CSA S806 recommends this equation for computing $\theta$ to be used, but following both the ACI 318 and CSA A23.3, it also stipulates that $\theta$ may not be taken less than $30^{\circ}$ nor greater than $60^{\circ}$.

\section{Zhou's Model}

The Zhou's model is based on the method of Kojima et al. (1997) and is similar to the pre-1998 ACI code approach and is only applicable to PC members. In this model $T_{n}$ can be calculated by summing the contribution of the concrete, $T_{n c}$, and the contribution of the reinforcement, $T_{n s}$ to the torsional resistance as

$T_{n}=T_{n c}+T_{n s}$

According to this model the torsional failure of a FRPRC/PC member may be initiated by rupture of transverse or longitudinal reinforcement, and torsional strength is reached whichever occurs first. Zhou adopted this method but introduced a modification factor that takes into account the difference between the FRP and steel mechanical properties. $T_{n c}$ can be calculated by using

$T_{n c}=\gamma k\left(1-2 \frac{t_{w}}{b}\right)^{2}\left(1-2 \frac{t_{w}}{b}\right), \gamma=\sqrt{1+\frac{\sigma_{p}}{f_{t}}}$,

where $b$ is the member width, $f_{t}$ is the tensile strength of concrete, $\gamma$ is the factor that take into account the effective prestress, $\sigma_{p}$ is the effective prestress.

$k$ is given by:

$k=T_{t e}+0.25\left(T_{t p}-T_{t e}\right)\left(\frac{f_{b}}{f_{t}}-1\right)\left(5-\frac{f_{b}}{f_{t}}\right)$,

where $f_{b}$ is the modulus of rupture of concrete.

$T_{t e}$ and $T_{t p}$ are computed using:

$T_{t e}=b^{2} h f_{t} \frac{1}{3+1.8 \frac{b}{h}}$

where $h$ is the overall height of the member.

$T_{t e}=0.5 b^{2} h f_{t}\left(1-\frac{b}{3 h}\right)$.

The torsional resistance provided by transverse reinforcement, $T_{n t s}$, is calculated using

$T_{n t s}=2 A_{o h} \frac{A_{F t} f_{F u t}}{\gamma s} \sqrt{\frac{E_{F t}}{E_{s}}}$.

The torsional resistance provided by the longitudinal reinforcement, $T_{n l s}$, is computed as

$T_{n l s}=2 A_{o h} \frac{A_{F t} f_{F u l}}{\gamma P_{h}} \sqrt{\frac{E_{F}}{E_{S}}}+2 A_{o h} \frac{\sigma_{p} t_{w}}{\gamma}$,

where $E_{s}$ is the modulus of elasticity of steel (200 GPa), $E_{F t}$ is the modulus of elasticity of the transverse reinforcements, $f_{F u l}$ is the ultimate strengths of the FRP longitudinal reinforcement, $f_{F u t}$ is the ultimate strengths of the FRP transverse reinforcement.

Note that the angle $\theta$ is not directly considered in these equations, but is assumed to be equal to $45^{\circ}$. 
According to Zhou's model in the case of combined torsion and bending actions it is possible to use the Swamy formula:

$\left(\frac{T_{n}}{T_{0}}\right)^{2}+\left(\frac{M_{n}}{M_{0}}\right)^{2}=1$

where $T_{n}$ and $M_{n}$ are the torsional and the ultimate bending strength, respectively and $T_{0}$ and $M_{0}$ are the pure torsional and pure bending ultimate strength of the section, respectively.

\section{Collection of Experimental Data}

Experimental data of FRP-RC and FRP-PC beams subjected to combined torsion, shear and flexure, available in literature (Zhou, 1997; Yonekura et al., 1994), were analysed and collected in a database. The relevant geometric and material properties of the beams are given in Table 1. The details of the mechanical properties with the experimental results are given in Table 2. In all these tests, the beams had a rectangular cross section. The internal reinforcements used were either CFRP or AyFRP bars.

Table 1. Geometric data and material properties of FRP-RC/PC beams tested under combined actions.

\begin{tabular}{|c|c|c|c|c|c|c|c|c|c|c|}
\hline \multirow[b]{2}{*}{ Data source } & \multirow{2}{*}{$\begin{array}{l}\text { Specimen } \\
\text { name }\end{array}$} & \multicolumn{2}{|c|}{ Geometric data } & \multirow{2}{*}{$\begin{array}{c}\text { Concrete } \\
f_{c} \\
(\mathrm{MPa})\end{array}$} & \multirow{2}{*}{$\begin{array}{c}\text { Prestress } \\
\sigma_{P} \\
(\mathrm{MPa})\end{array}$} & \multirow{2}{*}{$\begin{array}{r}\text { Load } \\
T / M\end{array}$} & \multicolumn{4}{|c|}{ FRP longitudinal reinforcement } \\
\hline & & $\begin{array}{c}b \\
(\mathrm{~mm})\end{array}$ & $\begin{array}{c}h \\
(\mathrm{~mm})\end{array}$ & & & & Type & $\begin{array}{c}A_{l} \\
\left(\mathrm{~mm}^{2}\right)\end{array}$ & $\begin{array}{c}f_{l} \\
(\mathrm{MPa})\end{array}$ & $\begin{array}{c}E_{l} \\
(\mathrm{GPa})\end{array}$ \\
\hline \multirow{8}{*}{$\begin{array}{c}\& \\
\text { Yonekura et al. } \\
\text { (1994) }\end{array}$} & A1 & 140 & 220 & 49.0 & - & 0.3 & AFRP & 172.0 & 1860 & 53 \\
\hline & $\mathrm{A} 2$ & 140 & 220 & 49.0 & 12.24 & 0.3 & AFRP & 172.0 & 1860 & 53 \\
\hline & A3 & 140 & 220 & 49.0 & 11.28 & 0.3 & AFRP & 172.0 & 1860 & 53 \\
\hline & A4 & 140 & 220 & 49.0 & 11.19 & 0.3 & AFRP & 172.0 & 1860 & 53 \\
\hline & A5 & 140 & 220 & 49.0 & 11.68 & 0.3 & AFRP & 516.0 & 1860 & 53 \\
\hline & A6 & 140 & 220 & 49.0 & 11.92 & 1.2 & AFRP & 172.0 & 1860 & 53 \\
\hline & A7 & 140 & 220 & 78.0 & 11.77 & 1.2 & AFRP & 172.0 & 1860 & 53 \\
\hline & A8 & 140 & 220 & 49.0 & 11.49 & 1.2 & AFRP & 516.0 & 1860 & 53 \\
\hline \multirow{13}{*}{$\begin{array}{c}\text { Zhou } \\
\text { (1997) } \\
\& \\
\text { Yonekura et al. } \\
\text { (1994) }\end{array}$} & C1 & 140 & 220 & 49.0 & - & 0.3 & CFRP & 201.2 & 2110 & 136 \\
\hline & $\mathrm{C} 2$ & 140 & 220 & 49.0 & - & 0.3 & CFRP & 839.6 & 1910 & 129 \\
\hline & C3 & 140 & 220 & 49.0 & 9.17 & 0.3 & CFRP & 201.2 & 2110 & 136 \\
\hline & $\mathrm{C} 4$ & 140 & 220 & 49.0 & 12.23 & 0.3 & CFRP & 201.2 & 2110 & 136 \\
\hline & C5 & 140 & 220 & 49.0 & 12.32 & 0.3 & CFRP & 201.2 & 2110 & 136 \\
\hline & C6 & 140 & 220 & 49.0 & 12.32 & 0.3 & CFRP & 839.6 & 1910 & 129 \\
\hline & $\mathrm{C} 7$ & 140 & 220 & 49.0 & 9.10 & 1.2 & CFRP & 201.2 & 2110 & 136 \\
\hline & C8 & 140 & 220 & 49.0 & 12.40 & 1.2 & CFRP & 201.2 & 2110 & 136 \\
\hline & C9 & 140 & 220 & 49.0 & - & 1.2 & CFRP & 201.2 & 2110 & 136 \\
\hline & C10 & 140 & 220 & 49.0 & 12.38 & 1.2 & CFRP & 201.2 & 2110 & 136 \\
\hline & C11 & 140 & 220 & 49.0 & 11.52 & 1.2 & CFRP & 201.2 & 2110 & 136 \\
\hline & C12 & 140 & 220 & 78.0 & 11.77 & 1.2 & CFRP & 201.2 & 2110 & 136 \\
\hline & C13 & 140 & 220 & 49.0 & 12.76 & 1.2 & CFRP & 839.6 & 1910 & 129 \\
\hline
\end{tabular}

Note: $b=$ member width; $h=$ member overall height; $f_{c}^{\prime}=$ concrete cylinder compressive strength; $\sigma_{P}=$ effective prestress; $T=$ torsional moment; $M=$ bending moment; $A_{l}, f_{l}, E_{l}=$ area, ultimate strength, and elasticity modulus of longitudinal reinforcements.

\section{Comparison of the Theoretical Previsions Against Experimental Data}

In Table 3, for the beams listed in Table 1 and in Table 2 , the experimental failure load, $P_{\text {exp }}$, and its corresponding theoretical value, $P_{t h}$, computed according the two methods analyzed are given for each beam. For the CSA S806 method the angle of inclination $\theta$ is shown in the table, while it's omitted for the Zhou's model since it is assume $\theta=45^{\circ}$. Moreover, for all the beams the mean value of the ratio $P_{\exp } / P_{t h}$, its standard deviation and coefficient of variation are also given. When calculating the ultimate capacity of each beam by either method, the material resistance factors were set equal to one. In the case of the Zhou's model the mean value of the ratio $P_{\exp } / P_{t h}$ is 0.95 , with a standard deviation of 0.33 while the corresponding values for the CSA method are 1.12 and 0.22 . It can be noticed that this model overestimates the capacity of the RC beams, while the capacity of PC beams is underestimated by over $50 \%$ in some cases. The Canadian Standard generally predicts the strength of the same beams more accurately, but it seems to overestimate the capacity of the RC beams with high amount of longitudinal reinforcement. On the whole, the method gives rea- 
sonable results for both the AFRP and the CFRP reinforced and prestressed beams. Therefore, the design strength of all the beams according to CSA S806 would be on the safe side, even if other relevant statistical variables were factored in (Fig. 1(a)). While in the case of the Zhou's model some of the beam are on the unsafe side (Fig. 1(b)).

Table 2. Mechanical properties and experimental results of FRP-PC and FRP-RC beams tested under combined actions.

\begin{tabular}{|c|c|c|c|c|c|c|c|c|c|c|}
\hline \multirow{2}{*}{ Data source } & \multirow{2}{*}{$\begin{array}{l}\text { Specimen } \\
\text { name }\end{array}$} & \multicolumn{5}{|c|}{ FRP transverse reinforcement } & \multirow[b]{2}{*}{$\begin{array}{r}P_{\exp } \\
(\mathrm{kN})\end{array}$} & \multirow[b]{2}{*}{$\begin{array}{c}T_{\exp } \\
(\mathrm{kNm})\end{array}$} & \multirow[b]{2}{*}{$\begin{array}{c}M_{\exp } \\
(\mathrm{kNm})\end{array}$} & \multirow[b]{2}{*}{$\begin{array}{r}V_{\text {exp }} \\
(\mathrm{kN})\end{array}$} \\
\hline & & Type & $\begin{array}{c}A_{t} \\
\left(\mathrm{~mm}^{2}\right)\end{array}$ & $\begin{array}{c}f_{t} \\
\text { (MPa) }\end{array}$ & $\begin{array}{c}E_{t} \\
(\mathrm{GPa})\end{array}$ & $\begin{array}{c}s \\
(\mathrm{~mm})\end{array}$ & & & & \\
\hline \multirow{8}{*}{$\begin{array}{c}\text { Zhou } \\
\text { (1997) } \\
\& \\
\text { Yonekura et al. } \\
\text { (1994) }\end{array}$} & A1 & AFRP & 28.3 & 1860 & 53 & 70 & 67 & 4.82 & 16.07 & 33 \\
\hline & A2 & AFRP & 28.3 & 1860 & 53 & 70 & 113 & 8.13 & 27.10 & 56 \\
\hline & A3 & AFRP & 28.3 & 1860 & 53 & 40 & 121 & 8.73 & 29.10 & 61 \\
\hline & A4 & AFRP & 12.6 & 1860 & 53 & 40 & 110 & 7.89 & 26.30 & 55 \\
\hline & A5 & AFRP & 28.3 & 1860 & 53 & 70 & 109 & 7.86 & 26.20 & 55 \\
\hline & A6 & AFRP & 28.3 & 1860 & 53 & 70 & 30 & 8.67 & 7.23 & 15 \\
\hline & A7 & AFRP & 28.3 & 1860 & 53 & 70 & 38 & 10.85 & 9.04 & 19 \\
\hline & A8 & AFRP & 28.3 & 1860 & 53 & 70 & 29 & 8.38 & 6.98 & 15 \\
\hline \multirow{13}{*}{$\begin{array}{c}\text { Zhou } \\
\text { (1997) } \\
\text { \& } \\
\text { onekura et al. } \\
\text { (1994) }\end{array}$} & C1 & CFRP & 28.3 & 1670 & 118 & 110 & 63 & 4.50 & 15.00 & 31 \\
\hline & $\mathrm{C} 2$ & CFRP & 28.3 & 1670 & 118 & 110 & 77 & 5.56 & 18.53 & 39 \\
\hline & C3 & CFRP & 28.3 & 1670 & 118 & 110 & 101 & 7.26 & 24.20 & 50 \\
\hline & $\mathrm{C} 4$ & CFRP & 28.3 & 1670 & 118 & 110 & 125 & 9.02 & 30.07 & 63 \\
\hline & C5 & CFRP & 28.3 & 1670 & 118 & 110 & 117 & 8.40 & 28.00 & 58 \\
\hline & C6 & CFRP & 28.3 & 1670 & 118 & 110 & 111 & 7.96 & 26.53 & 55 \\
\hline & C7 & CFRP & 28.3 & 1670 & 118 & 110 & 29 & 8.38 & 6.98 & 15 \\
\hline & C8 & CFRP & 28.3 & 1670 & 118 & 110 & 33 & 9.61 & 8.01 & 17 \\
\hline & C9 & CFRP & 28.3 & 1670 & 118 & 110 & 19 & 5.42 & 4.52 & 9 \\
\hline & C10 & CFRP & 28.3 & 1670 & 118 & 110 & 34 & 9.84 & 8.20 & 17 \\
\hline & C11 & CFRP & 28.3 & 1670 & 118 & 40 & 43 & 12.24 & 10.20 & 21 \\
\hline & C12 & CFRP & 28.3 & 1670 & 118 & 40 & 45 & 13.02 & 10.85 & 23 \\
\hline & C13 & CFRP & 28.3 & 1670 & 118 & 110 & 31 & 8.94 & 7.45 & 16 \\
\hline
\end{tabular}

Note: $A_{t}, f_{t}, E_{t}=$ area, ultimate strength, and modulus of elasticity of transversal reinforcements; $s=$ transversal reinforcements spacing; $P_{\text {exp }}=$ load attained at failure; $T_{\text {exp }}, M_{\text {exp }}, V_{\text {exp }}=$ failure torsional moment, bending moment, shear force, measured in the test.
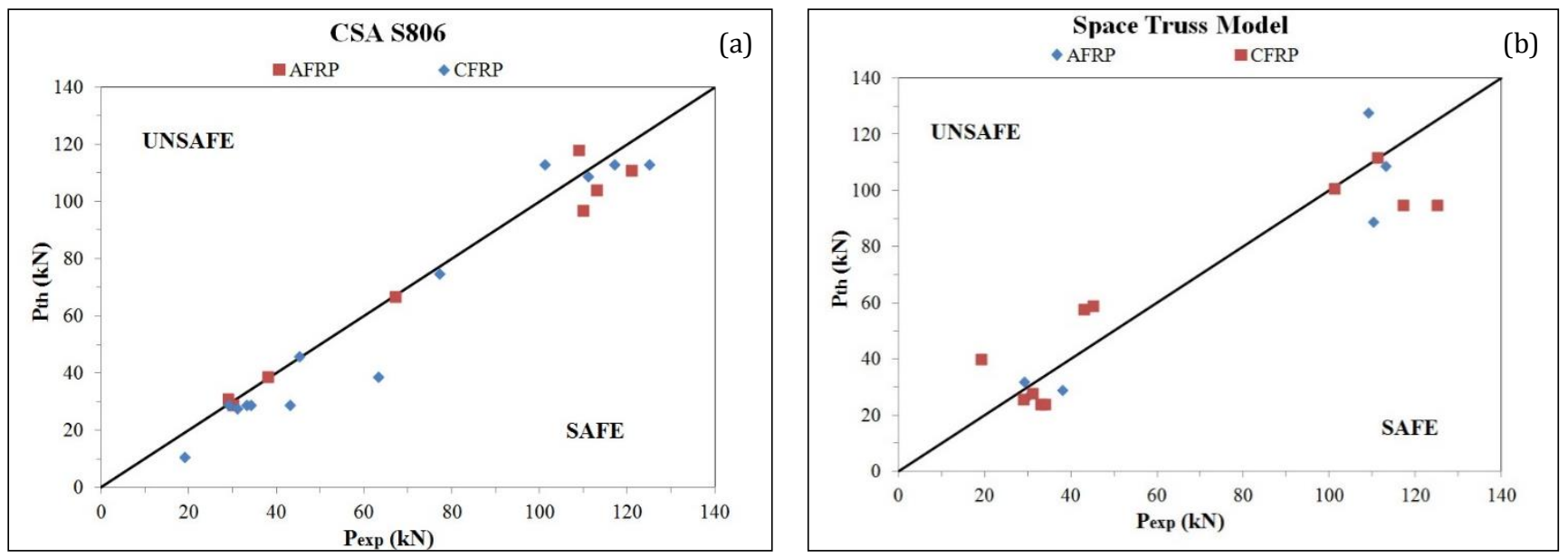

Fig. 1. Comparison of experimental data with theoretical provisions: a) CSA S806, b) Space truss model. 
Table 3. Comparison between theoretical and experimental failure loads.

\begin{tabular}{|c|c|c|c|c|c|c|c|}
\hline \multirow[b]{2}{*}{ Data source } & \multirow{2}{*}{$\begin{array}{l}\text { Specimen } \\
\text { name }\end{array}$} & \multirow[b]{2}{*}{$\begin{array}{c}P_{\exp } \\
(\mathrm{kN})\end{array}$} & \multicolumn{3}{|c|}{ CSA S806 } & \multicolumn{2}{|c|}{ Zhou } \\
\hline & & & $\begin{array}{c}P_{t h} \\
(\mathrm{kN})\end{array}$ & $P_{\exp } / P_{\text {th }}$ & $\begin{array}{c}\theta \\
\left({ }^{\circ}\right)\end{array}$ & $\begin{array}{c}P_{\text {th }} \\
(\mathrm{kN})\end{array}$ & $P_{\text {exp }} / P_{t h}$ \\
\hline \multirow{8}{*}{$\begin{array}{c}\text { Zhou } \\
\text { (1997) } \\
\& \\
\text { Yonekura et al. } \\
\text { (1994) }\end{array}$} & $\mathrm{A} 1$ & 67 & 67 & 1.00 & 60 & 150 & 0.45 \\
\hline & A2 & 113 & 104 & 1.09 & 48 & 109 & 1.04 \\
\hline & A3 & 121 & 111 & 1.09 & $60^{*}$ & 171 & 0.71 \\
\hline & A4 & 110 & 97 & 1.13 & 42 & 89 & 1.24 \\
\hline & A5 & 109 & 118 & 0.92 & $50^{*}$ & 128 & 0.85 \\
\hline & A6 & 30 & 29 & 1.03 & $37 *$ & 27 & 1.11 \\
\hline & A7 & 38 & 39 & 0.97 & 37 & 29 & 1.31 \\
\hline & A8 & 29 & 31 & 0.94 & $52^{*}$ & 32 & 0.91 \\
\hline \multirow{16}{*}{$\begin{array}{c}\text { Zhou } \\
\text { (1997) } \\
\& \\
\text { Yonekura et al. } \\
\text { (1994) }\end{array}$} & $\mathrm{C} 1$ & 63 & 39 & 1.62 & 60 & 161 & 0.39 \\
\hline & $\mathrm{C} 2$ & 77 & 75 & 1.03 & 49 & 203 & 0.38 \\
\hline & C3 & 101 & 113 & 0.89 & $30^{*}$ & 101 & 1.00 \\
\hline & $\mathrm{C} 4$ & 125 & 113 & 1.11 & $30 *$ & 95 & 1.32 \\
\hline & C5 & 117 & 113 & 1.04 & $30^{*}$ & 95 & 1.23 \\
\hline & C6 & 111 & 109 & 1.02 & $33^{*}$ & 112 & 0.99 \\
\hline & C7 & 29 & 29 & 1.00 & 30 & 26 & 1.12 \\
\hline & C8 & 33 & 29 & 1.14 & 30 & 24 & 1.38 \\
\hline & C9 & 19 & 11 & 1.73 & 56 & 40 & 0.48 \\
\hline & C10 & 34 & 29 & 1.17 & 30 & 24 & 1.42 \\
\hline & C11 & 43 & 29 & 1.48 & $36^{*}$ & 58 & 0.74 \\
\hline & $\mathrm{C} 12$ & 45 & 46 & 0.98 & $30^{*}$ & 59 & 0.76 \\
\hline & C13 & 31 & 28 & 1.11 & $30^{*}$ & 28 & 1.11 \\
\hline & \multicolumn{3}{|c|}{ Mean } & 1.12 & & & 0.95 \\
\hline & \multicolumn{3}{|c|}{ Standard deviation } & 0.22 & & & 0.33 \\
\hline & \multicolumn{3}{|c|}{ Coefficient of variation } & 0.20 & & & 0.35 \\
\hline
\end{tabular}

* failure governed by concrete crushing

\section{Conclusions}

The following main conclusions can be drawn from this study:

- The capacity of FRP reinforced and prestressed concrete members under combined action of flexure, shear and torsion can be accurately determined by using the proposed design provisions of the Canadian Standard CSA S806.

- With reference to the Canadian Standard, the mean value of the ratio of the experimental to theoretical strength ratio is 1.12 , with a standard deviation of 0.22 .

- The mean value of experimental to theoretical strength based ratio based on the space truss model is 0.95 , with a standard deviation of 0.33 . Furthermore, the method underestimates the strength of many beams, some by over $50 \%$. Accordingly, this method requires further improvement before it can be used in design.

- Additional test data involving a wider range of shear, torsion and flexure ratios, in addition to the internal reinforcement amount and arrangement, are needed to fully validate the proposed CSA S806 method and its reliability.

\section{REFERENCES}

AASHTO LRFD (2012). Bridge Design Specifications. American Association of State Highway and Transportation Official, Washington, DC.

Ascione L, Mancusi G, Spadea S (2010). Flexural behaviour of concrete beams reinforced with GFRP bars. Strain, 46(5), 460-469.

Ascione L, Razaqpur AG, Spadea S (2014). Effectiveness of FRP stirrups in concrete beams subject to shear. Proceedings of the 7th International Conference on FRP Composites in Civil Engineering (CICE 2014). ACI 440.1R (2006). Guide for the design and construction of structural concrete reinforced with FRP bars. American Concrete Institute, Farmington Hills, MI.

ACI 440.4R (2004). Prestressed concrete structures with FRP tendons. American Concrete Institute, Farmington Hills, MI.

ACI 318 (2011). Building code requirements for structural concrete and commentary. American Concrete Institute, Farmington Hills, MI.

CNR-DT 203 (2006). Guide for the design and construction of concrete structures reinforced with fiber-reinforced polymer bars. National Research Council CNR, Rome, Italy.

CSA A23.3 (2004) (Reaffirmed 2010). Design of concrete structures. Canadian Standards Association, Rexdale, Ontario, Canada.

CSA S806 (2012). Design and construction of building components with fibre-reinforced polymers. Canadian Standards Association, Rexdale, Ontario, Canada. 
Collins MP, Mitchell D (1997). Prestressed Concrete Structures. Response Publication, Canada.

Collins MP, Mitchell D, Adebar PE, Vecchio FJ (1996). A general shear design method. ACI Structural Journal, 93(1), 36-45.

El-Awady E, Husain M, Mandour S (2013). FRP-Reinforced concrete beams under combined torsion and flexure. International Journal of Engineering Science and Innovative Technology, 2(1), 384-393.

Elfgren L, Karlsson I, Losberg A (1974). Torsion-bending-shear interaction for concrete beams. Journal of Structural Division, 100(8), $1657-1676$

Eurocode 2 (2004). Design of concrete structures - Part 1-1: general rules and rules for buildings. EN 1992-1-1:2004, European Committee for Standardization.

Fib 40 (2007). FRP reinforcement in RC structures. International Federation for Structural Concrete.

JSCE (1997). Recommendation for design and construction of concrete structures using continuous fiber reinforcing materials. Concrete Engineering, Series 23.

Kanakubo T, Shindo M (1997). Shear behavior of fiber-mesh reinforced plates. Proceedings of the 3rd International Symposium on Non-Metallic (FRP) Reinforcement for Concrete Structures - International Symposium, Sapporo, Japan, October, 2, 317-324.

Kojima T, Takagi N, Uegaki Y (1991). Study on ultimate torque of prestressed reinforced concrete beams with large section subjected to pure torsion. Transaction of the Japan Concrete Institute, 13, 553560.

Navarro-Gregori J, Miguel-Sosa P, Fernandez-Prada MA, Filippou FC (2007). A 3D numerical model for reinforced and prestressed concrete elements subjected to combined axial, bending, shear and torsion loading. Engineering Structures, 29, 3404-3419.

Prabaghar A, Kumaran G (2011). Theoretical study on the behaviour of rectangular concrete beams reinforced internally with GFRP reinforcements under pure torsion. International Journal of Civil and Structural Engineering, 2(2), 570-594.

Rabbat B, Collins MP (1978). A variable angle space truss model for structural concrete members subjected to complex loading. In: International Symposium on Concrete and Concrete Structures. SP-55. Detroit: American Concrete Institute, 547-587.

Ragab KS, Eisa AS (2013). Torsion behaviour of steel fibered high strength self compacting concrete beams reinforced by GFRP bars. International Journal of Civil Science and Engineering, 7(9), 218-228.

Rahal KN (2007). Combined torsion and bending in reinforced and prestressed concrete beams using simplified method for combined stress-resultants. ACI Structural Journal, 104(4), 402-411.

Rahal KN, Collins MP (1999). Background of the general method of shear design in the 1994 CSA-A23.3 Standard. Canadian Journal of Civil Engineering, 26(6), 827-839.

Razaqpur AG, Rizzuti L, Bencardino F, Spadea G (2011). FRP-PC members: evaluation of torsional capacity. In ACIC 2011 conference on advanced composites in construction, Warwick, UK, 6-8 September, 319-328.

Razaqpur AG, Spadea S (2014). Shear strength of FRP reinforced concrete members with stirrups. Journal of Composites for Construction, 19(1).

Swamy RN (1962). The behavior and ultimate strength of prestressed concrete hollow beams under combined bending and torsion. Magazine of Concrete Research, 14(40), 13-24.

Zhou P (1997). Mechanical characteristics of prestressed concrete beams and columns with fiber reinforced plastics. Report, University of Hiroshima, Japan.

Yonekura A, Tazawa E, Zhou P, Sumi H (1994). Mechanical behavior of prestressed concrete beams with FRP rods subjected to combined bending and torsional moments. Transaction of the Japan Concrete Institute, 16, 217-224. 